\title{
The Chinese skeleton: insights into microstructure that help to explain the epidemiology of fracture
}

\author{
Elaine Cong and Marcella D Walker
}

Osteoporotic fractures are a major public health problem worldwide, but incidence varies greatly across racial groups and geographic regions. Recent work suggests that the incidence of osteoporotic fracture is rising among Asian populations. Studies comparing areal bone mineral density and fracture across races generally indicate lower bone mineral density in Asian individuals including the Chinese, but this does not reflect their relatively low risk of non-vertebral fractures. In contrast, the Chinese have relatively high vertebral fracture rates similar to that of Caucasians. The paradoxically low risk for some types of fractures among the Chinese despite their low areal bone mineral density has been elucidated in part by recent advances in skeletal imaging. New techniques for assessing bone quality non-invasively demonstrate that the Chinese compensate for smaller bone size by differences in hip geometry and microstructural skeletal organization. Studies evaluating factors influencing racial differences in bone remodeling, as well as bone acquisition and loss, may further elucidate racial variation in bone microstructure. Advances in understanding the microstructure of the Chinese skeleton have not only helped to explain the epidemiology of fracture in the Chinese, but may also provide insight into the epidemiology of fracture in other races as well.

Bone Research (2014) 2, 14009; doi:10.1038/boneres.2014.9; published online: 10 June 2014

\section{INTRODUCTION}

Fragility fractures represent a major public health problem worldwide with enormous societal and economic burdens. ${ }^{1-5}$ Assuming current age-specific hip fracture rates, approximately half of the world's hip fractures will occur in Asia by the year 2050. ${ }^{6}$ However, given the rising age-specific hip fracture rates among Asians, and in particular the Chinese, as compared to stable or declining rates elsewhere in the world, these projections are actually underestimated. ${ }^{7-8}$ In China, as many as 88.26 million individuals are currently estimated to have osteoporosis based on bone density measurement. ${ }^{9}$ Additionally, in the United States (US), the Asian population, traditionally considered at high risk for osteoporosis, has grown faster than any other racial group in the US over the last decade. ${ }^{10-12}$ Therefore, understanding the key determinants predisposing or protecting the Chinese against osteoporotic fracture is an important public health initiative for the twentyfirst century.

Decreased bone strength is a key risk factor for osteoporotic fracture. ${ }^{13}$ Bone mass is an important determinant of strength and accounts for the majority of the bone's resistance to fracture. ${ }^{14-15}$ Bone mass has historically been assessed as areal bone mineral density (aBMD) by dualenergy X-ray absorptiometry (DXA). However because aBMD represents a two-dimensional BMD measurement (i.e., in $\mathrm{g} \cdot \mathrm{cm}^{-2}$ ), it is affected by bone size and/or weight. Therefore, DXA tends to underestimate the true threedimensional or volumetric BMD (VBMD) in those with small body/bone size while overestimating it in those with large body/bone size. ${ }^{16-19}$ Also, while aBMD measurements by DXA represent the current gold standard for fracture risk prediction, it does not encompass the other aspects of bone quality such as bone microarchitecture, matrix composition, size, geometry and turnover. Therefore, in some circumstances, using DXA alone to evaluate bone strength fails to take into account key information that could be useful in understanding and predicting fracture risk.

Comparative studies have found that racial differences in $\mathrm{ABMD}$ as assessed by DXA do not adequately explain fracture differences between races. Despite lower aBMD at both vertebral and non-vertebral sites, the Chinese have a paradoxically lower non-vertebral fracture incid-

New York Presbyterian Hospital, New York, USA

Correspondence: MD Walker (mad2037@columbia.edu)

Received: 28 February 2014; revised: 18 April 2014; accepted: 18 April 2014 
ence versus Caucasians. ${ }^{20-23}$ This paradox may in part be explained by differences in hip geometry conferring greater resistance to compressive, buckling and impact forces in the Chinese. ${ }^{24-25}$ Additionally, recent advances in imaging technology that allow in vivo visualization of the bone's microarchitecture, as well as its size and volumetric bone mineral density, have provided further insight into racial variation in fracture rates. These imaging tools include high-resolution peripheral quantitative computed tomography (HRpQCT), central quantitative computed tomography (CQCT) and micromagnetic resonance imaging, as well as applied techniques such as individual trabecular segmentation (ITS), micro-finite element analysis ( $\mu \mathrm{FEA}$ ) and the trabecular bone score (TBS). Studies employing these technologies illustrate that the Chinese skeleton compensates for smaller bone size by advantages in both cortical and trabecular bone compartments that confer greater bone strength as compared to Caucasians. ${ }^{26-30}$ Taken together, these new insights into bone microstructure and other aspects of bone quality build upon prior DXA data to more comprehensively explain the epidemiology of fracture in the Chinese.

\section{EPIDEMIOLOGY OF FRACTURE IN THE CHINESE VERSUS OTHER RACES}

Vertebral fractures

The age-specific prevalence of vertebral fractures is similar in Asians versus Caucasians, though comparisons of vertebral fracture rates across races and regions have been confounded by differences in diagnostic methodology (Table 1)..$^{31-36}$ In the Hong Kong Osteoporosis Study, the prevalence of vertebral fractures in postmenopausal women over 45 years old was $22 \% .{ }^{31,36}$ A smaller study in 481 Hong Kong Chinese postmenoapusal women aged 70-79 years old cited a prevalence rate of $30 \% .{ }^{33} \mathrm{~A}$ study in Taiwan found a similar prevalence rate of $20 \%$ in women over age $65 .{ }^{37}$ These estimates are consistent with the $25 \%$ prevalence rate cited for US white postmenopausal women aged $65-70$ years old in one study, and $22 \%$ for those aged 70-79 years old and 34\% for women aged 80 and above in another study. ${ }^{33,38-39}$ In the Beijing
Osteoporosis Project, vertebral fracture prevalence rates were compared to that of US whites in both a Rochester Minnesota (MN) cohort and and the Multicenter Study of Osteoporotic Fractures cohort. ${ }^{40}$ In this study, the vertebral fracture prevalence rate was $15 \%$ overall in postmenopausal Chinese women over 50 years old. This rate increased steeply with age, from $5 \%$ in $50-59$ year olds to $37 \%$ among women aged 80 years or older. While the agespecific prevalence rates were similar between the Chinese and Multicenter Study of Osteoporotic Fractures cohorts, the age-specific prevalence of vertebral fractures was $5.5 \%$ lower in the Chinese versus the Rochester MN cohort.

Whereas the Beijing Osteoporosis Project found similar or lower age-specific vertebral fracture prevalence rates between Chinese and US cohorts, the Hong Kong Osteoporosis Project reported a more dramatic increase in vertebral fracture incidence rates with age in Asian versus Swedish Caucasian women. ${ }^{31}$ Although vertebral fracture inicidence rates rose near linearly with age in Caucasian women, they rose exponentially with age in women from Hong Kong and Japan. In Asian women over 80 years of age, the incidence was nearly double that of the Caucasian cohort.

There are less data in Chinese men. One study indicated that the prevalence rate of vertebral fractures in Chinese men older than 65 years is approximately $13 \%$, which is, as expected, lower than that reported in Chinese women but similar to rates described in Caucasian men. ${ }^{37}$ The Hong Kong Osteoporosis Project also found a similar incidence rate of vertebral fractures among the Chinese, Japanese and Swedish Caucasian male cohorts. ${ }^{31}$ The vertebral fracture incidence rate also rose in a similarly near linear fashion with age in all groups.

\section{Non-vertebral fractures}

In contrast to vertebral fractures, most studies indicate that Asians and Asian Americans have a relatively low hip fracture incidence compared to other races despite having lower aBMD (Figure 1)..$^{4,20-23}$ While less data are available, wrist and/or forearm osteoporotic fractures are also

Table 1. Prevalence of vertebral fractures among men and women, in different populations $\mathrm{s}^{33,36-37,39-40,92-93}$

\begin{tabular}{|c|c|c|c|c|}
\hline Race & Population/study & Age/years & Gender & Prevalence $/ \%$ \\
\hline \multirow[t]{6}{*}{ Chinese } & Hong Kong Osteoporosis Study & $>45$ & Female & 22 \\
\hline & Hong Kong & 70-79 & Female & 30 \\
\hline & Beijing Osteoporosis Study & $>50$ & Female & 15 \\
\hline & Taiwan & $>65$ & Female & 20 \\
\hline & Taiwan & $>65$ & Male & 13 \\
\hline & Weighted average vertebral fracture prevalence (Chinese): $19 \%$ & & & \\
\hline \multirow[t]{3}{*}{ US whites } & Study of Osteoporotic Fractures & $65-70$ & Female & 25 \\
\hline & Study of Osteoporotic Fractures & $65-99$ & Female & 20 \\
\hline & Rochester, MN & $>50$ & Female & 26 \\
\hline
\end{tabular}




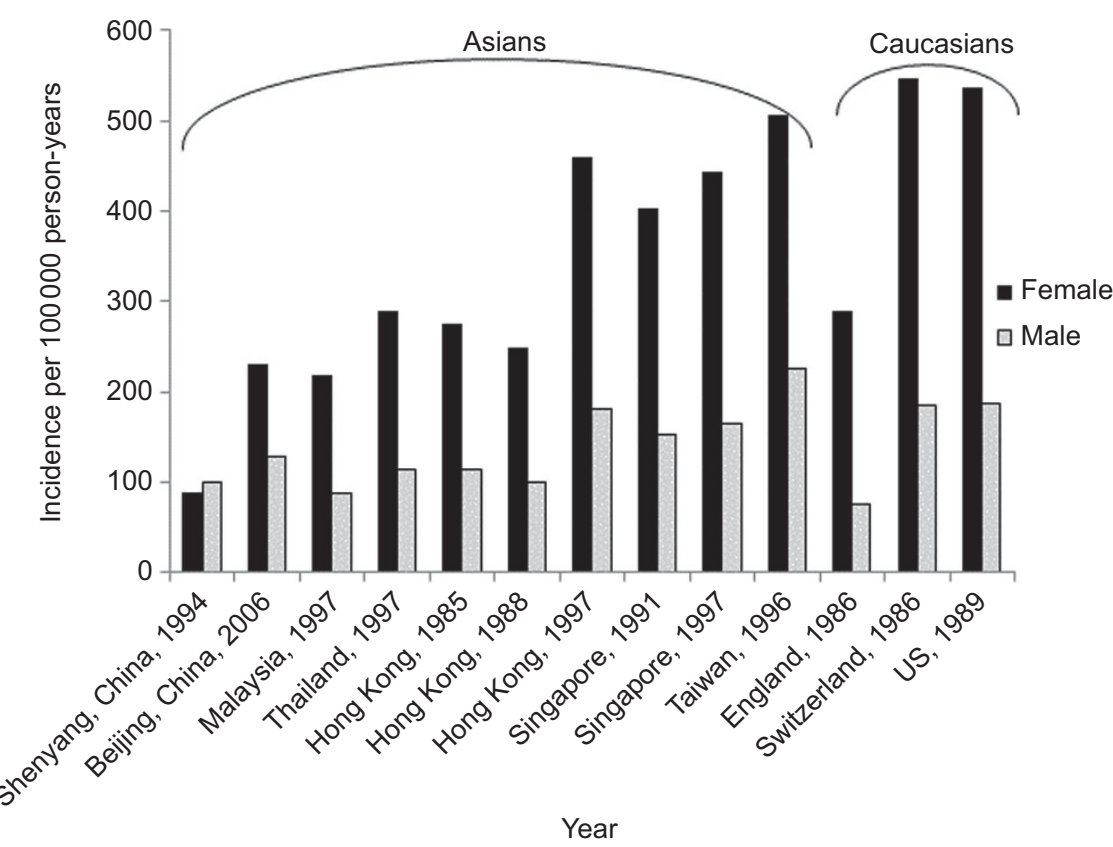

Figure 1. Hip fracture incidence per 100000 person-years in Asian and Caucasian women and men, in different populations. ${ }^{7,23,46-47,50-51,58,91,117}$ Data from Refs. 7, 45, 47 and 50 standardized to US population.

thought to occur less frequently in Asians compared with many other races/ethnicities. ${ }^{20,41}$

Among Asian American subgroups in the US, one study found that the incidence of hip fracture was the lowest in Chinese Americans compared to Japanese or Korean Americans. ${ }^{22}$ A retrospective study in Northern California compared fracture risk in South Asian, Chinese American and white postmenopausal women. Despite having the lowest aBMD, Chinese Americans also had the lowest non-vertebral fracture risk as compared to South Asians and whites, who had similar fracture rates at the wrist and other non-vertebral sites such as the humerus and hip. $^{42}$

Among Chinese living in Asia, hip fracture incidence is lowest in mainland China, ${ }^{21,43-44}$ while incidence among Asians living in Singapore and Taiwan is higher and similar to that of US whites. ${ }^{7,45-47}$ Studies in Hong Kong Chinese have shown varying results, with some demonstrating lower and others showing similar hip fracture rates versus that of US whites. ${ }^{7,31,45-46}$ Of concern, however, is that age-adjusted hip fracture rates in many Asian countries are recently rising by as much as $140 \%-250 \%$, in contrast to stabilizing or decreasing hip fracture rates in Western populations. ${ }^{4,7,48-49}$ The reasons for these temporal and geographic trends are unclear, but could be due to increasing globalization occurring more rapidly in some areas of Asia than others. ${ }^{4,49}$ In Hong Kong, as in Singapore and Taiwan, the rise in development and affluence has been postulated to contribute to a more sedentary lifestyle with less weight bearing activity, conferring a greater hip fracture risk. ${ }^{43-44,46}$ In contrast, a study conducted in the less affluent city of Shenyang in mainland China found that the residents maintained a high level of physical activity such as long-distance bicycle riding and stair climbing even into older age. ${ }^{50}$ In this population as well as in a study in Bejing, China, age-adjusted hip fracture incidence rates among men and women over 50 years old were $25 \%-80 \%$ less than those reported in US white populations. $^{21,50}$ In Shenyang, China, the standardized hip fracture incidence per 100000 person-years was low at 87 in females and 100 in males, respectively. ${ }^{50}$ In Beijing, China, the standardized hip fracture incidence per 100000 person-years in two separate studies was similarly low, ranging between 87 and 229 in females and 97 and 129 in males, respectively. ${ }^{21,49}$ By comparison, three white US population cohorts had much higher hip fracture incidence per 100000 person-years, ranging from 510 to 559 in women and 174 to 207 in men, respectively. ${ }^{7,23,51}$

Similarly, in a study comparing Hong Kong Chinese versUs US white women and men, the age-adjusted hip fracture incidence per 100000 person-years from 1988 to 1989 was approximately $50 \%$ lower in the Hong Kong cohort (247 versus 535 in women; and 100 versus 187 in men). ${ }^{7}$ In both populations, hip fracture incidence increased by age and with female gender. These findings were corroborated by the Hong Kong Osteoporosis Study undertaken in 1995, which demonstrated that hip fracture rates were $50 \%$ lower in men and women aged 50 or older versus age-matched Swedish Caucasians. ${ }^{31}$ Again, hip fractures increased with age in both groups, but in a linear 
fashion in the Hong Kong cohort versus an exponential increase in the Swedish Caucasian cohort. However, in the Asian Osteoporosis Study comparing the incidence of hip fracture from 1997 to 1998 in Hong Kong, Singapore, Malaysia and Thailand, the highest rates occcurred in Hong Kong, which shared a similar hip fracture incidence as that of US whites. ${ }^{45}$ Because the time periods assessed in the Hong Kong and Asian Osteoporosis Studies occurred in close proximity, the higher fracture rate in the latter study is unlikely to be solely explained by increasing fracture rates over time. In the Asian Osteoporosis Study, the age-adjusted hip fracture incidence per 100000 person-years among both Hong Kong women and men was $96 \%$ of that of the US white population in 1989, which had an incidence of 535 in women and 187 in men. The ageadjusted hip fracture incidence per 100000 person-years for women and men, respectively, in each Asian country was: 459 and 180 in Hong Kong; 442 and 164 in Singapore; 238 and 114 in Thailand; and 218 and 88 in Malaysia. A study in Taiwan Chinese versus US whites demonstrated a similar or higher age-adjusted hip fracture incidence per 100000 person-years of 505 versus 535 in women and 225 versus 187 in men. ${ }^{46}$

Fewer studies have examined wrist/distal forearm fractures, but the available data suggest that the incidence is also lower in Asians versus Caucasians. In an Oslo study, the relative risk of distal forearm fracture in Asians who immigrated to Oslo was 0.72 (95\% Cl: 0.53-1.00) compared to ethnic Norwegians living in Oslo. ${ }^{41}$ In the US, one study indicated a lower risk of wrist fractures in Asian American versus white, Hispanic and Native American postmenopausal women. ${ }^{20}$ Both Asian and African Americans shared a similarly low risk of fractures, although these two groups represent opposite ends of the spectrum with respect to aBMD.

\section{RACIAL DIFFERENCES IN AREAL BONE MINERAL DENSITY}

Because aBMD represents a two-dimensional BMD measurement, racial differences in ABMD must be evaluated with respect to racial differences in skeletal size and weight. Studies in adult Asians living in Asia and the US have typically demonstrated lower aBMD in comparison to whites and other racial groups. ${ }^{16,20,52-54}$ However, weight and/or bone size explains some of these differences. ${ }^{16,20,55-57}$ For example, in the Study of Women's Health Across the Nation (SWAN), unadjusted aBMD was lower among Asian American compared to white and black women. ${ }^{16}$ However, after adjustment for weight and other covariates, lumbar spine and femoral neck aBMD became greater in Chinese and Japanese Americans compared to white women. In addition, adjustment for weight eliminated differences in lumbar spine
ABMD and attenuated $A B M D$ differences at the femoral neck between Asian American versus black women. Similarly, a study in men ages 65-78 years across seven races in four countries found that adjustment for weight and height attenuated or reversed the differences in aBMD between US white and Asian men, including US Asian, Hong Kong Chinese and South Korean men. ${ }^{58}$

Notably, in most other races, variation in aBMD tends to correspond to and account for at least some of the racial differences in observed fracture rates. By contrast, the incongruent relationship between $\mathrm{ABMD}$ and fracture rates in Asians has been difficult to adequately explain. While low weight and smaller bone size explain the lower aBMD among Asians, these factors would tend to increase fracture risk if all other risk factors were equivalent between races. Therefore, several non-skeletal factors have been hypothesized to account for the low fracture rates seen in Asians, such as shorter height, ${ }^{46}$ lower incidence or severity of falls $s^{59-60}$ and differences in soft tissue thickness. ${ }^{61-64}$ While these factors may contribute to the lower non-vertebral fracture rates in Asians, recent advances in imaging technology demonstrate that differences in bone quality including macro- and microstructure and mechanical competence also play a role in fracture risk differences in the Chinese versus other races.

\section{HIP GEOMETRY AND ESTIMATED MECHANICAL COMPETENCE}

Differences in hip geometry between races have been proposed to contribute to the decreased rate of hip fractures in Asians versus whites despite similar or lower ABMD. Hip axis length (HAL) refers to the distance from the base of the greater trochanter through the femoral neck to the inner pelvic brim (Figure 2a). ${ }^{65}$ Femoral neck axis length (FNAL) is HAL minus the acetabular width, or the distance from the base of the greater trochanter to the apex of the
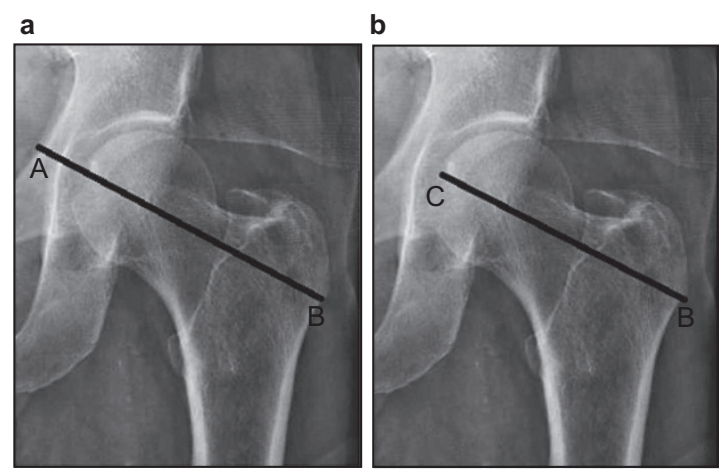

Figure 2. Representative hip geometry images indicating (a) Hip Axis Length, defined as the distance from the base of the greater trochanter through the femoral neck to the inner pelvic brim (point B to A) and (b) Femoral Neck Axis Length, defined as the distance from the base of the greater trochanter to the apex of the femoral head (point B to C). 
femoral head (Figure 2b). ${ }^{66}$ In the Study of Osteoporotic Fractures, longer HAL was an independent predictor of hip fracture in postmenopausal white women, with each standard deviation of HAL increase doubling the hip fracture risk, after adjustment for age, femoral neck aBMD, height and weight. ${ }^{65}$ Other studies have demonstrated similar results. ${ }^{67-68}$ However, one study found that FNAL, which is directly correlated with HAL, did not differ between hip fracture and age-matched non-hip fracture patients after adjustment for height. ${ }^{69}$ Therefore, studies correlating fracture risk with HAL or FNAL need to be adjusted for height.

In Asians, several studies worldwide have noted shorter HAL versus other races both in adult males and females, as well as in adolescent males. ${ }^{70-72}$ FNAL has also been shown to be shorter in both genders among Asians versus whites. ${ }^{73}$ A cross sectional study including young adult Chinese from China and Southeast Asia as compared to Australian Caucasians postulated that Chinese females and males reached peak growth velocity sooner with earlier epiphyseal closure and therefore had shorter leg length and FNAL. $^{73}$ Among studies in adults, the US Study of Osteoporotic Fractures demonstrated that the mean HAL of Asian American and black women was significantly shorter than that of whites by 1.2 and 0.7 standard deviations, respectively. ${ }^{70}$ Similarly, a study comparing Chinese men and women versus two Caucasian European cohorts showed that after adjustment for bone area, weight and height, the Chinese had significantly shorter HAL, neck length and neck diameter, despite no difference in ABMD. ${ }^{71}$

Building upon HAL and FNAL measurements, composite indices of femoral neck strength integrating body size with femoral neck bone size and aBMD have also shown advantages among Asians versus other races both in the US and China. ${ }^{24-25,74-75}$ In the SWAN study, a composite index of femoral neck strength assessing ability to withstand compressive loads, bending forces and impact from falls was calculated from femoral neck bone size and aBMD. As compared to white women, Chinese, Japanese and African American women all had higher composite strength indices even after adjusting for age, body mass index and menopause status. ${ }^{24}$ Few studies have associated racial differences in femoral neck strength to actual fracture rate differences, but a study in China found that higher compressive strength indices were associated with lower hip fracture risk in Chinese men and women versus US whites after adjusting for age, sex and height. ${ }^{25}$

\section{BONE MICROARCHITECTURE AND INSIGHTS INTO FRACTURE}

While understanding bone macroarchitecture and geometry is important, recent microarchitecture data have provided additional insights into our understanding of racial differences in fracture rates at the various skeletal sites. Bone microarchitecture is a key determinant of bone quality, bone strength and fracture risk. ${ }^{76-79}$ Recent advances in imaging technology and associated analytic tools not only shed light on microstructure, but also provide bone mineral density measurements that are independent of body size. Previously, with DXA alone, one could not distinguish between the cortical or outer dense envelope of the bone which predominantly comprises the appendicular skeleton and the trabecular or inner compartment of the bone containing individual distinct trabeculae which predominantly comprises the axial skeleton. However, some of these important elements of bone quality can now be measured non-invasively via HRPQCT of the forearm and distal tibia sites, CQCT of the spine and hip, micromagnetic resonance imaging and the TBS. Improved measurement of bone quality and bone strength may ultimately improve fracture risk prediction. To date, only HRPQCT, CQCT and TBS have been used to assess racial differences in bone quality. All methods can be used to assess volumetric bone density independent of bone size. In addition, HRPQCT and CQCT have the ability to assess bone size and differentiate between the trabecular and cortical compartments. Furthermore, HRpQCT can provide detail with regards to trabecular microarchitecture.

\section{CQCT: lumbar spine VBMD}

In a study of 83 premenopausal and 50 postmenopausal Chinese American and white women, CQCT was used to assess differences in bone size, structure and VBMD at the lumbar spine and hip. ${ }^{80}$ Before adjustment for covariates, there were no differences in lumbar spine VBMD between white and Chinese American women, but vertebral bone size was smaller among postmenopausal Chinese American versus white women. Lumbar spine trabecular VBMD was $5.8 \%$ greater in premenopausal Chinese American versus white women after adjustment for differences in weight, height, physical activity, total calcium intake, parathyroid hormone and 25-hydroxyvitamin D. In contrast, there were no differences seen in postmenopausal Chinese American versus white women in lumbar spine integral or trabecular VBMD or vertebral bone size after adjustment for covariates. This finding of no difference between races in bone mass and bone size in postmenopausal women is consistent with data showing comparable vertebral fracture rates between postmenopausal Chinese and Caucasian women.

CQCT: hip VBMD

In contrast to the findings at the vertebrae, the same study demonstrated greater VBMD at the total hip and femoral neck in the pre- and postmenopausal Chinese American 
versus white women. ${ }^{80}$ Among premenopausal women, Chinese American women had greater integral and cortical VBMD at the femoral neck and greater integral VBMD at the total hip. Among postmenopausal women, Chinese American women had greater cortical VBMD at the femoral neck and total hip, but no differences in integral or trabecular VBMD at either site. While unadjusted femoral neck bone size (i.e., cross-sectional area) was smaller in both pre- and postmenopausal Chinese American versus white women, these differences were attenuated with adjustment for covariates. There were no differences in the ratio of tissue in the cortical region of the total hip and femoral neck to total tissue volume within the periosteal boundaries (i.e., the proportion of total bone volume that is cortical bone, a surrogate for cortical thickness). In summary, the greater cortical femoral neck and total hip volumetric bone density as measured by CQCT may provide greater bone strength despite a smaller bone size, and therefore, may contribute to the lower hip fracture incidence observed in postmenopausal Chinese American versus white women.

Similar advantages in hip volumetric bone density and microstructure were seen in Asian American men in the MrOs study, a study involving white, African American, Hispanic and Asian American men 65 years and older. CQCT analyses indicated that Asian and African American men had $6 \%-10 \%$ greater integral and $33 \%-$ $36 \%$ greater trabecular $\mathrm{VBMD}$, as well as $5 \%$ greater cortical thickness at the hip site compared with white men. The authors suggested that these differences might confer improved bone strength and account for the lower rates of hip fracture in Asian and African American men compared to whites. $^{81}$

HRPQCT: forearm and distal tibia volumetric BMD and microstructure

Several studies have indicated that cortical and trabecular microstructural deterioration, as measured by HRPQCT, is associated with fragility fractures. Specifically lower total and trabecular VBMD, cortical and trabecular thickness, and trabecular number; and higher trabecular separation and inhomogeneity have been associated with both vertebral and non-vertebral fractures at the distal radius, hip and proximal humerus. ${ }^{63,82-84}$ With regard to racial differences in HRPQCT, in a study of premenopausal women comparing 31 Chinese American to 32 white women, aBMD by DXA did not differ between groups at any skeletal site, including the lumbar spine, hip or forearm. ${ }^{29}$ However, HRPQCT at the radius demonstrated greater trabecular and cortical density; trabecular bone to tissue volume (BV/TV); and trabecular and cortical thickness both before and after adjustment for covariates in the Chinese American cohort. Analysis by HRPQCT at the tibia revealed similar findings as well as higher trabecular number, lower trabecular spacing and inhomogeneity after adjustment for covariates. Bone size was smaller in Chinese American versus white women at both sites before adjustment for covariates, with the difference attenuated after adjustment.

Similar HRPQCT findings were observed in a study of white and Chinese premenopausal women in Australia, whereby thicker cortices and trabeculae organized within a smaller bone was hypothesized to confer a lower fracture risk at the radius and tibia. ${ }^{30}$ These microstructural advantages have also been observed in Asian adolescents and young adults in Canada. ${ }^{85}$ After adjusting for covariates, Canadian adolescent and young adult South and Southeast Asian males had greater cortical bone density and thickness compared with Caucasian males. ${ }^{85}$ Asian females in Canada also had greater cortical VBMD and thickness and lower trabecular spacing than Caucasian females after adjusting for covariates.

In a cohort of white and Chinese American premenopausal women, ITS and $\mu \mathrm{FEA}$ were applied to HRPQCT images in order to further elucidate racial differences in bone microarchitecture and strength. ${ }^{28}$ ITS is a relatively novel technique developed by DrX. Edward Guo, in which the morphology of individual trabeculae are assessed as either rod-like or plate-like. More plates and/or a higher plate to rod ratio are associated with greater mechanical competence (i.e., estimated strength) and lower risk of fragility fracture. ${ }^{86-89} \mu \mathrm{FEA}$ is another methodology used to estimate the mechanical competence of bone from HRPQCT images, by simulating bone under deformation conditions. ${ }^{63,90}$ The results of ITS showed that while premenopausal Chinese American women had a similar number of rod-like trabeculae, they had more trabecular plates (i.e., higher plate bone volume fraction and plate number density), leading to a higher plate-to-rod ratio and greater trabecular connectivity (plate-rod junction density) at both the distal radius and tibia (Figure $3 a$ and $b$ ). ${ }^{28}$ By using $\mu \mathrm{FEA}$, these differences in trabecular bone microstructure were shown to translate into a greater trabecular mechanical competence $155 \%-68 \%$ at the distal radius and 29\%-43\% at the distal tibia) in premenopausal Chinese American versus white women. Despite smaller bone size, thicker cortices and more plate-like trabecular bone in premenopausal Chinese American women led to $14 \%$ and $8 \%$ greater whole-bone stiffness at the radius and tibia, respectively, versus whites. Racial differences in ITS were not as great among postmenopausal white and Chinese American women. However, postmenopausal Chinese American women also had a higher trabecular plate-to-rod ratio and greater whole bone stiffness, despite similar trabecular density as compared to postmenopausal white women. ${ }^{26}$ Thus, studies in Asians 
a

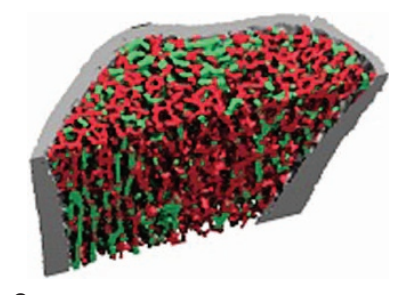

c

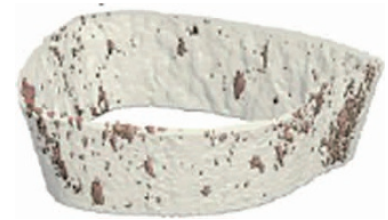

d
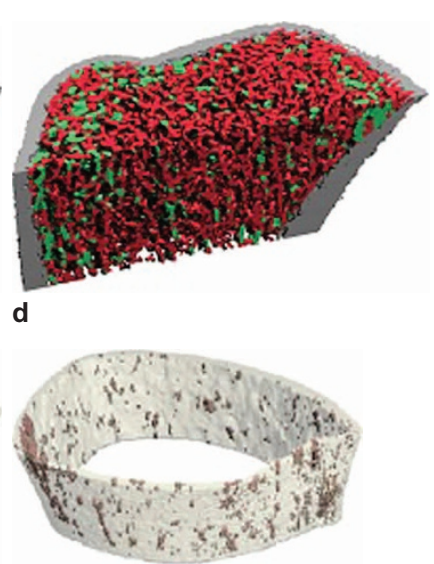

Figure 3. Representative HRpQCT images indicating smaller bone size but thicker cortices and more plate- (green) versus rod-like (red) trabeculae at the radius in premenopausal (a) Chinese American versus (b) white women; three-dimensional representations of lower cortical porosity in premenopausal (c) Chinese American versus (d) white women at the tibia

across multiple geographic locations indicate that microstructural advantages in bone quality may compensate for smaller bone size. The resultant overall increase in bone strength is consistent with the lower rates of non-vertebral fractures in Asians versus whites.

Using an automated segmentation technique, the cortical bone compartment of HRPQCT images can be further analyzed. Thicker and denser cortical bone is thought to confer greater resistance to fracture, discriminate fracture from non-fracture subjects and carry most of the load even at distal sites. ${ }^{84,91-92}$ Microstructural properties within cortical bone that are important to fracture resistance and strength include cortical porosity and mineralization assessed as tissue mineral density (TMD). ${ }^{93}$ In one study, each standard deviation increase in cortical porosity increased the odds of fracture by $22 \%-55 \%$ depending upon the skeletal site..$^{51}$ This method has been used in two studies to assess differences between Chinese and white individuals. ${ }^{85,94}$ In one study, both pre- and postmenopausal Chinese American women had greater cortical thickness, cortical tissue mineral density and reduced cortical porosity at both the radius and tibia (Figure $3 c$ and d), all of which contributed to greater cortical VBMD, better skeletal integrity and greater resistance to fracture as compared to whites. ${ }^{94}$ With regard to the individual contribution of various aspects of cortical microarchitecture to whole bone stiffness, cortical TMD was the most significant single predictor of bone stiffness at both radial and tibial sites. However, cortical porosity, area and TMD in combination all played a role in determining whole bone stiffness. In another study, Canadian adolescent and young adult South and Southeast Asian males also had greater cortical porosity than Caucasian males after adjusting for covariates but this difference was not observed in females. ${ }^{85}$ Higher cortical whole bone stiffness may explain the lower rates of cortical (forearm) fractures in Asian individuals as compared to whites and other racial groups. Whether all of these findings can be extrapolated to central sites to explain the lower risk of hip fracture is not clear.

\section{TBS}

The TBS is a relatively new technique that provides a quantitative estimate of trabecular microarchitecture derived from a grey-scale textural analysis using variograms of $2 D$ lumbar spine DXA projection images. ${ }^{95}$ Similar to $C Q C T$, TBS is independent of bone size. ${ }^{95} \mathrm{~A}$ higher TBS is directly correlated with trabecular number, separation and connectivity density and predicts fracture risk in postmenopausal women. ${ }^{96-97}$ In the only published study done using TBS to assess racial differences in bone quality, lumbar spine TBS was compared to $C Q C T$ and HRPQCT indices in pre- and postmenopausal Chinese American and white women. ${ }^{98}$ TBS correlated most highly with $C Q C T$ but also with HRPQCT VBMD and microarchitectural measurements, except for radial cortical thickness and tibial trabecular thickness. In addition, TBS in combination with aBMD predicted more variance in $C Q C T$ lumbar spine measurement than $\mathrm{ABMD}$ alone. Similar to the unadjusted $C Q C T$ findings in the same cohort, no differences were found by TBS between race in either pre- or postmenopausal women both before and after adjustment for covariates. Taken together, CQCT and TBS demonstrate that Chinese American and white women share similar vertebral bone mass, size and microarchitecture. These results are congruent with vertebral fracture data showing comparable rates between the two races.

These findings demonstrate that the Chinese skeleton has advantages at both central (hip) and peripheral sites. The microstructural features present in Chinese individuals lead to greater mechanical competence via organization of denser bone with more connectivity and less porosity on a smaller cross-sectional surface than that of its Caucasian counterpart. These microstructural and mechanical differences clarify what was previously a paradox and may potentially play a role in accounting for the differences in fracture rates seen in Asians versus Caucasians.

\section{RACIAL DIFFERENCES IN BONE TURNOVER AND BONE ACQUISITION AND LOSS}

Although advances in imaging have better delineated the microstructural and mechanical underpinnings for differences in fracture rates seen among Asians versus Caucasians, the underlying physiological reasons accounting for these observations remain unclear. In Japanese and Chinese populations, bone turnover markers have been positively correlated with hip and vertebral 
fracture risk and negatively correlated with $\mathrm{aBMD}$ at the lumbar spine, femoral neck and total hip..$^{99-103}$ However, few studies have compared racial differences in bone remodeling and its contribution to skeletal health. ${ }^{104}$ In the SWAN study, bone turnover markers as assessed by urinary $\mathrm{N}$-telopeptide of type I collagen and serum osteocalcin levels were highest in US whites versus Chinese and Japanese American women both before and after adjustment for covariates. ${ }^{104}$ These findings were consistent with the known racial variation in fracture rates reported in these populations. However, in this particular cohort, bone turnover markers were not correlated with aBMD differences and fracture rates were not documented.

Another area of interest is the potential role of sclerostin in contributing to racial differences in bone density and fracture rates by modulating bone remodeling. ${ }^{105-107}$ Sclerostin is an osteocyte-secreted protein encoded by the SOST gene that inhibits the anabolic Wnt signaling pathway and results in lower osteoblast-mediated bone formation. ${ }^{108-109}$ In Caucasian women, higher levels are associated with greater hip fracture risk independent of traditional risk factors. ${ }^{10}$ In the Chinese, serum sclerostin has been positively correlated with lumbar spine and femoral neck aBMD and negatively correlated with bone turnover markers. ${ }^{106-107}$ However, only one study has evaluated racial differences in sclerostin and no studies have correlated sclerostin levels with fracture in the Chinese. In a cohort of pre- and postmenopausal white and Chinese American women, one study assessed whether sclerostin levels and bone turnover markers explained racial variation in bone mass and microarchitecture. ${ }^{105}$ As expected based on prior studies, serum sclerostin was higher in post- versus premenopausal women and positively correlated with aBMD in both races. However, sclerostin levels did not differ by race and did not correlate with $\mathrm{VBMD}$ or microarchitecture in either pre- or postmenopausal cohorts. By contrast, bone turnover markers were lower in Chinese Americans. Further, pre- versus postmenopausal differences in bone turnover markers were smaller in the Chinese American versus white women, supporting the known racial differences in microarchitecture and fracture risk.

Racial differences in bone acquisition and bone loss are suggested by limited data but more research needs to be done. While few longitudinal studies have been performed in children and adolescents, one study found differences in the tempo of bone mass accrual, with black and Asian females and Asian males tending to reach a plateau in aBMD earlier than Hispanics and whites. ${ }^{111}$ Racial differences in rates of age-related and postmenopausal bone loss have also been reported. In the longitudinal SWAN study, Asian Americans had the most rapid vertebral spine aBMD loss over the peri-menopausal period, as compared to non-Hispanic whites and African Americans. ${ }^{12}$ However, the statistically significant absolute difference in bone loss by race or ethnicity was small $(1 \%-2 \%)$ and was accounted for by the lower weight among Asian Americans. ${ }^{12}$ In a cross-sectional study in Australia, Asian and white women both had similar net 'loss' in vertebral body bone mineral content due to greater endosteal bone 'loss' versus periosteal bone 'gain'. ${ }^{13}$ Net bone 'loss' was similar in Asian and white men, and less overall in men versus women. In another cross-sectional study, age-related differences between pre-versus postmenopausal Chinese American and white women were assessed. ${ }^{26}$ As expected, aBMD at each site and cortical thickness and density by HRPQCT were significantly lower in post- versus premenopausal women regardless of race, and the pre- versus postmenopausal differences were similar between Chinese American and white women. At both sites, cortical porosity more than doubled, while cortical TMD 'declined' by $3 \%$ at the radius and $6 \%-7 \%$ at the tibia between pre- and postmenopausal women in both races. Whole bone stiffness, trabecular bone density and trabecular plate parameters were also lower in post- versus premenopausal women. However, Chinese American women had greater pre- versus postmenopausal within-race differences in trabecular density as well as plate bone volume fracture (pBV/TV) at the radius and plate-plate and plate-rod connectivity at the tibia. These cross-sectional data may suggest that while Chinese women tend to have similar deterioration in the cortical compartment of bone across menopause, there is a more rapid 'loss' of trabecular bone compared to white women. While these data are consistent with prior studies showing greater relative risk for trabecular (vertebral) versus cortical (hip, forearm) fractures in the Chinese, prospective data are needed to confirm these results.

\section{IMPLICATIONS, LIMITATIONS, UNANSWERED QUESTIONS AND AREAS FOR FUTURE RESEARCH}

A limitation of the available data on racial variation in $B M D$, fracture and other parameters related to bone strength is the heterogeneity of individuals within even a single racial category. Asia encompasses multiple countries, and each country is comprised of a population with different ancestral and geographic roots as well as different lifestyles. For example, in Singapore, the population is multi-ethnic and includes Chinese, Malaysians and Southeast Indians. ${ }^{45}$ Therefore, it may be difficult to extrapolate findings from one study to another if the racial composition of the populations enrolled differs from one location to another. This heterogeneity also contributes to the challenge of defining a standard that represents the Asian population as a whole. 
In the absence of well-defined standards for nonCaucasian races, the 2013 International Society for Clinical Densitometry Guidelines recommend that the white female normative database be used for T-score calculations for women of all ethnic groups. ${ }^{114}$ However, because Asians tend to have smaller body/bone size, clinicians should interpret such DXA results with the understanding that lower aBMD in Asians may lead to a more frequent diagnosis of osteoporosis when a Caucasian referent is used to calculate T-scores. ${ }^{54}$ Thus, the available epidemiological fracture and microarchitectural data would suggest that fracture risk may be overestimated by DXA T-score particularly at the non-vertebral sites. While the FRAX tool has aided with fracture risk prediction from DXA in non-white individuals, the US Asian FRAX tool assumes that the fracture risk in Asian women and men is only $50 \%$ and $64 \%$ of their white counterparts, respectively. ${ }^{115}$ Some data suggest that actual fracture rates are higher, particularly in women at vertebral sites. ${ }^{31}$ Thus, using T-scores or FRAX may lead to over or under diagnosis and treatment respectively in Asians. In theory, several different approaches could be considered in the future such as utilizing different $T$-score thresholds for different sites or modifying FRAX so that the overall risk of osteoporotic fracture reflects the higher vertebral fracture risk. Both approaches, however, may be fraught with difficulty.

Unfortunately, at this time, there is no simple solution to resolve the clinical dilemmas that such data raise and it remains unclear how to best identify Asians at risk. While $V B M D$ and microarchitectureal data from advanced imaging techniques are consistent with fracture rates in Asians, it is not clear that such techniques predict future fracture more accurately than DXA in this group. While limited data from the Mr Os study suggest that finite element analysis-estimated vertebral strength better predicted new vertebral fractures than DXA in a multiethnic cohort of elderly men, much more data is needed. ${ }^{116}$ Further, advanced imaging techniques such as CQCT, HRPQCT and FEA are neither currently FDA-approved nor clinically available, and are unlikely to become widely available in many parts of the world in the near future. DXAderived indices that incorporate measures of composite hip strength and microarchitecture (i.e., TBS) along with $\mathrm{ABMD}$ may be a more practical approach in the future for providing a more comprehensive and individualized approach for fracture risk assessment in this group. Until more data are available, clinicians should be aware of the limitations and current areas of uncertainty regarding DXA and FRAX-derived osteoporotic fracture risk predictions when making clinical decisions in Asian populations.

\section{CONCLUSION}

Osteoporotic fractures remain a public health problem for all racial groups. Fracture rates are rapidly increasing within the countries in Asia and Southeast Asia. Delineating the macro- and microstructural and mechanical differences in the axial and appendicular skeleton between races is vital to understanding racial differences in bone strength and fracture risk. Paradoxically, despite a lower $\mathrm{aBMD}$, the Chinese have similar vertebral fracture rates but far fewer non-vertebral fractures than that of most other racial groups. Structural advantages in hip geometry such as shorter hip and femoral neck axial length may contribute to greater compressive and buckling strength. Furthermore, with newer imaging technology, we have also begun to shed light on microstructural differences contributing to racial differences in fracture risk. These studies have demonstrated that at the lumbar spine, a site rich in trabecular bone, postmenopausal Chinese and white women do not show any differences in volumetric bone mass, bone size or microarchitecture. Additionally, a number of studies suggest that bone loss, particularly at trabecular sites, may be greater in Chinese than white women. This finding is consistent with fracture data demonstrating equal or higher incidence of vertebral fractures among postmenopausal Chinese versus Caucasians. By contrast, studies across both genders, a spectrum of ages and a range of geographic regions, reveal that in the appendicular skeleton, which is rich in cortical bone, the Chinese have greater microstructural and mechanical advantages. This finding is consistent with their lower risk of hip and other non-vertebral fractures. Taken together, the insights gleaned from microstructure and biomechanical data have further illuminated the connection between the Chinese skeleton and fracture risk. Additionally, underlying these changes in microstructure may be racial variation in bone remodeling and its regulators that lead to differences in bone acquisition and loss. More prospective data relating microstructure, mechanical competence and bone remodeling to the prediction of fracture across races are needed. However, by continually building upon the existing foundation of knowledge through ongoing studies of the Chinese skeleton, we can further expand our ability to risk stratify individuals not only of Chinese descent but also of all other races.

\section{Conflict of interest}

The authors have no financial relationships to disclose and no conflicts of interest.

\section{Acknowledgements}

This work was supported by NIH grants K23 AR053507, a National Osteoporosis Foundation grant, and the Mary and David Hoar Fellowship 
Program of the New York Community Trust and the New York Academy of Medicine. We thank Clyde Wu for his vision and support of this study.

\section{References}

1 Cooper C, Atkinson EJ, Jacobsen SJ, O'Fallon WM, Melton LJ 3rd. Population-based study of survival after osteoporotic fractures. Am J Epidemiol 1993; 137: 1001-1005.

2 Chrischilles EA, Butler CD, Davis CS, Wallace RB. A model of lifetime osteoporosis impact. Arch Intern Med 1991; 151: 2026-2032.

3 Dempster DW. Osteoporosis and the burden of osteoporosis-related fractures. Am J Manag Care 2011; 17(Suppl 6): S164-S169.

4 Kanis JA, Oden A, McCloskey EV, Johansson H, Wahl DA, Cooper C. A systematic review of hip fracture incidence and probability of fracture worldwide. Osteoporos Int 2012; 23: 2239-2256.

5 Dai K, Zhang Q, Fan T, Sen SS, Osteoporotic Hip Fracture in China Study T. Estimation of resource utilization associated with osteoporotic hip fracture and level of post-acute care in China. Curr Med Res Opin 2007; 23: 2937-2943.

6 Cooper C, Campion G, Melton LJ 3rd. Hip fractures in the elderly: a world-wide projection. Osteoporos Int 1992; 2: 285-289.

7 Koh LK, Saw SM, Lee JJ, Leong KH, Lee J, National Working Committee on O. Hip fracture incidence rates in Singapore 1991-1998. Osteoporos Int 2001; 12: 311-318.

8 Cooper C, Cole ZA, Holroyd CR et al. Secular trends in the incidence of hip and other osteoporotic fractures. Osteoporos Int 2011; 22: 1277-1288.

9 Wu XP, Liao EY, Luo XH, Dai RC, Zhang H, Peng J. Age-related variation in quantitative ultrasound at the tibia and prevalence of osteoporosis in native Chinese women. Br J Radiol 2003; 76: 605-610.

10 Taylor AJ, Gary LC, Arora T et al. Clinical and demographic factors associated with fractures among older Americans. Osteoporos Int 2011; 22: 1263-1274.

11 Golden SH, Brown A, Cauley JA et al. Health disparities in endocrine disorders: biological, clinical, and nonclinical factors-an Endocrine Society scientific statement. J Clin Endocrinol Metab 2012; 97: E1579E1639.

12 Proximity One. America's Asian Population Patterns 2012. Available at http://proximityone.com/cen2010_asian.htm.

13 NIH Consensus Development Panel on Osteoporosis Prevention D, Therapy. Osteoporosis prevention, diagnosis, and therapy. JAMA 2001; 285: 785-795.

14 NIH Consensus Development Panel on Osteoporosis. Osteoporosis prevention, diagnosis and therapy. J Am Med Assoc 2001; 285: 785795.

15 Ammann P, Rizzoli R. Bone strength and its determinants. Osteoporos Int 2003; 14(Suppl 3): S13-S18.

16 Finkelstein JS, Lee ML, Sowers Met al. Ethnic variation in bone density in premenopausal and early perimenopausal women: effects of anthropometric and lifestyle factors. J Clin Endocrinol Metab 2002; 87: 3057-3067.

17 Russell-Aulet M, Wang J, Thornton JC, Colt EW, Pierson RN Jr. Bone mineral density and mass in a cross-sectional study of white and Asian women. J Bone Miner Res 1993; 8: 575-582.

18 Carter DR, Bouxsein ML, Marcus R. New approaches for interpreting projected bone densitometry data. J Bone Miner Res 1992; 7: 137-145.

19 Katzman DK, Bachrach LK, Carter DR, Marcus R. Clinical and anthropometric correlates of bone mineral acquisition in healthy adolescent girls. J Clin Endocrinol Metab 1991; 73: 1332-1339.

20 Barrett-Connor E, Siris ES, Wehren LE et al. Osteoporosis and fracture risk in women of different ethnic groups. J Bone Miner Res 2005; 20: 185194.
$21 \mathrm{Xu} \mathrm{L}$, Lu A, Zhao X, Chen X, Cummings SR. Very low rates of hip fracture in Beijing, People's Republic of China the Beijing Osteoporosis Project. Am J Epidemiol 1996; 144: 901-907.

22 Lauderdale DS, Jacobsen SJ, Furner SE, Levy PS, Brody JA, Goldberg J. Hip fracture incidence among elderly Asian-American populations. Am J Epidemiol 1997; 146: 502-509.

23 Silverman SL, Madison RE. Decreased incidence of hip fracture in Hispanics, Asians, and Blacks: California Hospital Discharge Data. Am J Public Health 1988; 78: 1482-1483.

24 Ishii S, Cauley JA, Greendale GA, Danielson ME, Safaei Nili N, Karlamangla A. Ethnic differences in composite indices of femoral neck strength. Osteoporos Int 2012; 23: 1381-1390.

$25 \mathrm{Yu}$ N, Liu YJ, Pei Y et al. Evaluation of compressive strength index of the femoral neck in Caucasians and Chinese. Calcif Tissue Int 2010; 87: 324332.

26 Walker MD, Liu XS, Zhou B et al. Pre- and postmenopausal differences in bone microstructure and mechanical competence in Chinese-American and white women. J Bone Miner Res 2013; 28: 1308-1318.

27 Walker MD, Liu XS, Stein E et al. Differences in bone microarchitecture between postmenopausal Chinese-American and white women. J Bone Miner Res 2011; 26: 1392-1398.

28 Liu XS, Walker MD, McMahon DJ et al. Better skeletal microstructure confers greater mechanical advantages in Chinese-American women versus white women. J Bone Miner Res 2011; 26: 1783-1792.

29 Walker MD, McMahon DJ, Udesky J, Liu G, Bilezikian JP. Application of high-resolution skeletal imaging to measurements of volumetric BMD and skeletal microarchitecture in Chinese-American and white women: explanation of a paradox. J Bone Miner Res 2009; 24: 1953-1959.

30 Wang XF, Wang Q, Ghasem-Zadeh A et al. Differences in macro- and microarchitecture of the appendicular skeleton in young Chinese and white women. J Bone Miner Res 2009; 24: 1946-1952.

31 Bow $\mathrm{CH}$, Cheung E, Cheung CL et al. Ethnic difference of clinical vertebral fracture risk. Osteoporos Int 2012; 23: 879-885.

32 Golden SH, Brown A, Cauley JA et al. Health disparities in endocrine disorders: biological, clinical, and nonclinical factors - an endocrine society scientific statement. J Clin Endocrinol Metab 2012; 97: E1579E1639.

33 Lau EM, Chan HH, Woo J et al. Normal ranges for vertebral height ratios and prevalence of vertebral fracture in Hong Kong Chinese: a comparison with American Caucasians. J Bone Miner Res 1996; 11: 1364-1368.

34 Ross PD, Fujiwara S, Huang C et al. Vertebral fracture prevalence in women in Hiroshima compared to Caucasians or Japanese in the US. Int J Epidemiol 1995; 24: 1171-1177.

35 Kung AW. Management of osteoporosis in Hong Kong. Clin Calcium 2004; 14: 108-111.

36 Tsang SW, Bow CH, Chu EY, Yeung SC, Soong CC, Kung AW. Clinical risk factor assessment had better discriminative ability than bone mineral density in identifying subjects with vertebral fracture. Osteoporos Int 2011; 22: 667-674.

37 Tsai K, Twu S, Chieng P, Yang R, Lee T. Prevalence of vertebral fractures in Chinese men and women in urban Taiwanese communities. Calcif Tissue Int 1996; 59: 249-253.

38 Melton LJ 3rd, Lane AW, Cooper C, Eastell R, O'Fallon WM, Riggs BL. Prevalence and incidence of vertebral deformities. Osteoporos Int 1993; 3 : 113-119.

39 Black DM, Cummings SR, Stone K, Hudes E, Palermo L, Steiger P. A new approach to defining normal vertebral dimensions. J Bone Miner Res 1991; 6: 883-892. 
40 Ling X, Cummings SR, Mingwei Q et al. Vertebral fractures in Beijing, China: the Beijing Osteoporosis Project. J Bone Miner Res 2000; 15: 20192025.

41 Lofthus CM, Frihagen F, Meyer HE, Nordsletten L, Melhuus K, Falch JA. Epidemiology of distal forearm fractures in Oslo, Norway. Osteoporos Int 2008; 19: 781-786.

42 Khandewal S, Chandra M, Lo JC. Clinical characteristics, bone mineral density and non-vertebral osteoporotic fracture outcomes among postmenopausal U.S. South Asian Women. Bone 2012; 51: 1025-1028.

43 Lau EM, Cooper C. Epidemiology and prevention of osteoporosis in urbanized Asian populations. Osteoporos Int 1993; 3(Suppl 1): 23-26.

44 Lau EM, Cooper C. The epidemiology of osteoporosis. The oriental perspective in a world context. Clin Orthop Relat Res 1996; (323): 65-74.

45 Lau EM, Lee JK, Suriwongpaisal P et al. The incidence of hip fracture in four Asian countries: the Asian Osteoporosis Study (AOS). Osteoporos Int 2001; 12: 239-243.

46 Lau EM, Suriwongpaisal P, Lee JK et al. Risk factors for hip fracture in Asian men and women: the Asian osteoporosis study. J Bone Miner Res 2001; 16: 572-580.

47 Chie WC, Yang RS, Liu JP, Tsai KS. High incidence rate of hip fracture in Taiwan: estimated from a nationwide health insurance database. Osteoporos Int 2004; 15: 998-1002.

48 Lau EM, Cooper C, Fung H, Lam D, Tsang KK. Hip fracture in Hong Kong over the last decade-a comparison with the UK. J Public Health Med 1999; 21: 249-250.

49 Ho SC, Bacon WE, Harris T, Looker A, Maggi S. Hip fracture rates in Hong Kong and the United States, 1988 through 1989. Am J Public Health 1993; 83: 694-697.

50 Yan L, Zhou B, Prentice A, Wang X, Golden MH. Epidemiological study of hip fracture in Shenyang, People's Republic of China. Bone 1999; 24: 151-155.

51 Bjornerem A, Bui QM, Ghasem-Zadeh A, Hopper JL, Zebaze R, Seeman E. Fracture risk and height: an association partly accounted for by cortical porosity of relatively thinner cortices. J Bone Miner Res 2013; 28: 2017-2026.

52 Woo J, Li M, Lau E. Population bone mineral density measurements for Chinese women and men in Hong Kong. Osteoporos Int 2001; 12: 289295.

53 Xiaoge D, Eryuan L, Xianping W et al. Bone mineral density differences at the femoral neck and Ward's triangle: a comparison study on the reference data between Chinese and Caucasian women. Calcif Tissue Int 2000; 67: 195-198.

54 Walker MD, Babbar R, Opotowsky AR et al. A referent bone mineral density database for Chinese American women. Osteoporos Int 2006; 17: 878-887.

55 Bhudhikanok GS, Wang MC, Eckert K, Matkin C, Marcus R, Bachrach LK. Differences in bone mineral in young Asian and Caucasian Americans may reflect differences in bone size. J Bone Miner Res 1996; 11: $1545-1456$.

56 Lau EM, Lynn H, Woo J, Melton LJ 3rd. Areal and volumetric bone density in Hong Kong Chinese: a comparison with Caucasians living in the United States. Osteoporos Int 2003; 14: 583-588.

57 Ross PD, He Y, Yates AJ et al. Body size accounts for most differences in bone density between Asian and Caucasian women. The EPIC (Early Postmenopausal Interventional Cohort) Study Group. Calcif Tissue Int 1996; 59: 339-343.

58 Nam HS, Shin MH, Zmuda JM et al. Race/ethnic differences in bone mineral densities in older men. Osteoporos Int 2010; 21: 2115-2123.

59 Bouxsein ML, Szulc P, Munoz F, Thrall E, Sornay-Rendu E, Delmas PD. Contribution of trochanteric soft tissues to fall force estimates, the factor of risk, and prediction of hip fracture risk. J Bone Miner Res 2007; 22: 825831.

60 Majumder S, Roychowdhury A, Pal S. Effects of trochanteric soft tissue thickness and hip impact velocity on hip fracture in sideways fall through 3D finite element simulations. J Biomech 2008; 41: 2834-2842.

61 Melton LJ 3rd, Riggs BL, Keaveny TM et al. Structural determinants of vertebral fracture risk. J Bone Miner Res 2007; 22: 1885-1892.

62 Stein EM, Liu XS, Nickolas TL et al. Abnormal microarchitecture and stiffness in postmenopausal women with ankle fractures. J Clin Endocrinol Metab 2011; 96: 2041-2048.

63 Boutroy S, van Rietbergen B, Sornay-Rendu E, Munoz F, Bouxsein ML, Delmas PD. Finite element analysis based on in vivo HR-pQCT images of the distal radius is associated with wrist fracture in postmenopausal women. J Bone Miner Res 2008; 23: 392-399.

64 Cohen A, Liu XS, Stein EM et al. Bone microarchitecture and stiffness in premenopausal women with idiopathic osteoporosis. J Clin Endocrinol Metab 2009; 94: 4351-4360.

65 Faulkner KG, Cummings SR, Black D, Palermo L, Gluer CC, Genant HK. Simple measurement of femoral geometry predicts hip fracture: the study of osteoporotic fractures. J Bone Miner Res 1993; 8: 1211-1217.

66 Peacock M, Turner CH, Liu G, Manatunga AK, Timmerman L, Johnston CC Jr. Better discrimination of hip fracture using bone density, geometry and architecture. Osteoporos Int 1995; 5: 167-173.

67 Duboeuf F, Hans D, Schott AM et al. Different morphometric and densitometric parameters predict cervical and trochanteric hip fracture: the EPIDOS Study. J Bone Miner Res 1997; 12: 1895-1902.

68 Geusens P. Geometric characteristics of the proximal femur and hip fracture risk. Osteoporos Int 1996; 6(Suppl 3): 27-30.

69 Center JR, Nguyen TV, Pocock NA et al. Femoral neck axis length, height loss and risk of hip fracture in males and females. Osteoporos Int 1998; 8: $75-81$.

70 Cummings SR, Cauley JA, Palermo L et al. Racial differences in hip axis lengths might explain racial differences in rates of hip fracture. Study of Osteoporotic Fractures Research Group. Osteoporos Int 1994; 4: 226-229.

71 Yan L, Crabtree NJ, Reeve J et al. Does hip strength analysis explain the lower incidence of hip fracture in the People's Republic of China? Bone 2004; 34: 584-588

72 Wang MC, Aguirre M, Bhudhikanok GS et al. Bone mass and hip axis length in healthy Asian, black, Hispanic, and white American youths. J Bone Miner Res 1997; 12: 1922-1935.

73 Wang XF, Duan Y, Beck TJ, Seeman E. Varying contributions of growth and ageing to racial and sex differences in femoral neck structure and strength in old age. Bone 2005; 36: 978-986.

74 Danielson ME, Beck TJ, Lian Y et al. Ethnic variability in bone geometry as assessed by hip structure analysis: findings from the hip strength across the menopausal transition study. J Bone Miner Res 2013; 28: 771-779.

75 Zhang F, Tan LJ, Lei SF, Deng HW. The differences of femoral neck geometric parameters: effects of age, gender and race. Osteoporos Int 2010; 21: 1205-1214.

76 Goulet RW, Goldstein SA, Ciarelli MJ, Kuhn JL, Brown MB, Feldkamp LA. The relationship between the structural and orthogonal compressive properties of trabecular bone. J Biomech 1994; 27: 375389.

77 Keaveny TM, Morgan EF, Niebur GL, Yeh OC. Biomechanics of trabecular bone. Annu Rev Biomed Eng 2001; 3: 307-333.

78 Kim HS, Al-Hassani ST. A morphological model of vertebral trabecular bone. J Biomech 2002; 35: 1101-1114.

79 van Rietbergen B, Odgaard A, Kabel J, Huiskes R. Relationships between bone morphology and bone elastic properties can be 
accurately quantified using high-resolution computer reconstructions. J Orthop Res 1998; 16: 23-28.

80 Walker MD, Saeed I, McMahon DJ et al. Volumetric bone mineral density at the spine and hip in Chinese American and White women. Osteoporos Int 2012; 23: 2499-2506.

81 Marshall LM, Zmuda JM, Chan BK et al. Race and ethnic variation in proximal femur structure and BMD among older men. J Bone Miner Res 2008; 23: 121-130.

82 Sornay-Rendu E, Boutroy S, Munoz F, Delmas PD. Alterations of cortical and trabecular architecture are associated with fractures in postmenopausal women, partially independent of decreased BMD measured by DXA: the OFELY study. JBone Miner Res 2007; 22: 425-433.

83 Boutroy S, Bouxsein ML, Munoz F, Delmas PD. In vivo assessment of trabecular bone microarchitecture by high-resolution peripheral quantitative computed tomography. J Clin Endocrinol Metab 2005; 90: 6508-6515.

84 Sornay-Rendu E, Cabrera-Bravo JL, Boutroy S, Munoz F, Delmas PD. Severity of vertebral fractures is associated with alterations of cortical architecture in postmenopausal women. J Bone Miner Res 2009; 24: 737743.

85 Kim S, Macdonald HM, Nettlefold L, McKay HA. A comparison of bone quality at the distal radius between Asian and Caucasian adolescents and young adults: an HR-pQCT study. J Bone Miner Res 2013; 28: 20352042.

86 Liu XS, Stein EM, Zhou B et al. Individual trabecula segmentation (ITS)based morphological analyses and microfinite element analysis of HRpQCT images discriminate postmenopausal fragility fractures independent of DXA measurements. J Bone Miner Res 2012; 27: 263-272.

87 Liu XS, Sajda P, Saha PK et al. Complete volumetric decomposition of individual trabecular plates and rods and its morphological correlations with anisotropic elastic moduli in human trabecular bone. J Bone Miner Res 2008; 23: 223-235.

88 Liu XS, Sajda P, Saha PK, Wehrli FW, Guo XE. Quantification of the roles of trabecular microarchitecture and trabecular type in determining the elastic modulus of human trabecular bone. J Bone Miner Res 2006; 21: 1608-1617.

89 Liu XS, Bevill G, Keaveny TM, Sajda P, Guo XE. Micromechanical analyses of vertebral trabecular bone based on individual trabeculae segmentation of plates and rods. J Biomech 2009; 42: 249-256.

90 Liu XS, Zhang XH, Sekhon KK et al. High-resolution peripheral quantitative computed tomography can assess microstructural and mechanical properties of human distal tibial bone. J Bone Miner Res 2010; 25: 746-756.

91 MacNeil JA, Boyd SK. Load distribution and the predictive power of morphological indices in the distal radius and tibia by high resolution peripheral quantitative computed tomography. Bone 2007; 41: 129-137.

92 Vico L, Zouch M, Amirouche A et al. High-resolution pQCT analysis at the distal radius and tibia discriminates patients with recent wrist and femoral neck fractures. J Bone Miner Res 2008; 23: 1741-1750.

93 Seeman E, Delmas PD. Bone quality - the material and structural basis of bone strength and fragility. N Engl J Med 2006; 354: 2250-2261.

94 Boutroy S, Walker MD, Liu XS et al. Lower cortical porosity and higher tissue mineral density in Chinese-American versus white women. J Bone Miner Res 2014; 29: 551-561.

95 Hans D, Barthe N, Boutroy S, Pothuaud L, Winzenrieth R, Krieg MA. Correlations between trabecular bone score, measured using anteroposterior dual-energy $\mathrm{X}$-ray absorptiometry acquisition, and 3dimensional parameters of bone microarchitecture: an experimental study on human cadaver vertebrae. J Clin Densitometry 2011; 14: $302-$ 312.
96 Hans D, Goertzen AL, Krieg MA, Leslie WD. Bone microarchitecture assessed by TBS predicts osteoporotic fractures independent of bone density: the Manitoba study. J Bone Miner Res 2011; 26: 2762-2769.

97 Boutroy S, Hans D, Sornay-Rendu E, Vilayphiou N, Winzenrieth R, Chapurlat $\mathrm{R}$. Trabecular bone score improves fracture risk prediction in non-osteoporotic women: the OFELY study. Osteoporos Int 2013; 24: 77-85.

98 Silva BC, Walker MD, Abraham A et al. Trabecular bone score is associated with volumetric bone density and microarchitecture as assessed by central QCT and HRpQCT in Chinese American and white women. J Clin Densitometry 2013; 16: 554-561.

99 Cheung CK, Panesar NS, Lau E, Woo J, Swaminathan R. Increased bone resorption and decreased bone formation in Chinese patients with hip fracture. Calcif Tissue Int 1995; 56: 347-349.

100 Zhao J, Xia W, Nie M et al. The levels of bone turnover markers in Chinese postmenopausal women: Peking Vertebral Fracture study. Menopause 2011; 18: 1237-1243.

$101 \mathrm{Hu}$ WW, Zhang Z, He JW et al. Establishing reference intervals for bone turnover markers in the healthy shanghai population and the relationship with bone mineral density in postmenopausal women. Int J Endocrinol 2013; 2013: 513925.

102 Tamaki J, Iki M, Kadowaki E et al. Biochemical markers for bone turnover predict risk of vertebral fractures in postmenopausal women over 10 years: the Japanese Population-based Osteoporosis (JPOS) Cohort Study. Osteoporos Int 2013; 24: 887-897.

103 Yan L, Prentice A, Zhou B et al. Age- and gender-related differences in bone mineral status and biochemical markers of bone metabolism in Northern Chinese men and women. Bone 2002; 30: 412-415.

104 Finkelstein JS, Sowers M, Greendale GA et al. Ethnic variation in bone turnover in pre- and early perimenopausal women: effects of anthropometric and lifestyle factors. J Clin Endocrinol Metab 2002; 87: 3051-3056

105 Costa AG, Walker MD, Zhang CA et al. Circulating sclerostin levels and markers of bone turnover in Chinese-American and white women. JClin Endocrinol Metab 2013; 98: 4736-4743.

$106 \mathrm{Xu} \mathrm{XJ}$, Shen L, Yang YP et al. Serum sclerostin levels associated with lumbar spine bone mineral density and bone turnover markers in patients with postmenopausal osteoporosis. Chin Med J 2013; 126: 2480-2484.

107 Sheng Z, Tong D, Ou Y et al. Serum sclerostin levels were positively correlated with fat mass and bone mineral density in central south Chinese postmenopausal women. Clin Endocrinol 2012; 76: 797-801.

108 Poole KE, van Bezooijen RL, Loveridge N et al. Sclerostin is a delayed secreted product of osteocytes that inhibits bone formation. FASEB J 2005; 19: 1842-1844.

109 van Bezooijen RL, ten Dijke P, Papapoulos SE, Lowik CW. SOST/ sclerostin, an osteocyte-derived negative regulator of bone formation. Cytokine Growth Factor Rev 2005; 16: 319-327.

110 Arasu A, Cawthon PM, Lui LY et al. Serum sclerostin and risk of hip fracture in older Caucasian women. J Clin Endocrinol Metab 2012; 97: 2027-2032.

111 Bachrach LK, Hastie T, Wang MC, Narasimhan B, Marcus R. Bone mineral acquisition in healthy Asian, Hispanic, Black, and Caucasian youth: a longitudinal study. J Clin Endocrinol Metab 1999; 84: 4702-4712.

112 Finkelstein JS, Brockwell SE, Mehta V et al. Bone mineral density changes during the menopause transition in a multiethnic cohort of women. $J$ Clin Endocrinol Metab 2008; 93: 861-868.

113 Duan Y, Wang XF, Evans A, Seeman E. Structural and biomechanical basis of racial and sex differences in vertebral fragility in Chinese and Caucasians. Bone 2005; 36: 987-998. 
114 Schousboe JT, Shepherd JA, Bilezikian JP, Baim S. Executive summary of the 2013 International Society for Clinical Densitometry Position Development Conference on bone densitometry. J Clin Densitometry 2013; 16: 455-466.

115 Cauley JA, El-Hajj Fuleihan G, Arabi A et al. Official Positions for FRAX(R) clinical regarding international differences from Joint Official Positions Development Conference of the International Society for Clinical Densitometry and International Osteoporosis Foundation on FRAX(R). J Clin Densitometry 2011; 14: 240-262.

116 Wang X, Sanyal A, Cawthon PMet al. Prediction of new clinical vertebral fractures in elderly men using finite element analysis of CT scans. J Bone Miner Res 2012; 27: 808-816.
117 Lau EM, Cooper C, Wickham C, Donnan S, Barker DJ. Hip fracture in Hong Kong and Britain. Int J Epidemiol 1990; 19: 1119-1121.

(c) (1) () $\Theta$ This work is licensed under a Creative Commons Attribution(1) No No Nommercial-NoDerivs 3.0 Unported License. The images or other third party material in this article are included in the article's Creative Commons license, unless indicated otherwise in the credit line; if the material is not included under the Creative Commons license, users will need to obtain permission from the license holder to reproduce the material. To view a copy of this license, visit http://creativecommons.org/licenses/by-nc-nd/3.0/ 